\title{
Patients' Self-Perceived Impacts and Prosthodontic Needs at the Time and after Tooth Loss
}

\author{
Linéia Tavares TEÓFILO \\ Cláudio Rodrigues LELES
}

Department of Prevention and Oral Rehabilitation, School of Dentistry, Federal University of Goiás, Goiânia, GO, Brazil

\begin{abstract}
Studies on self-perception have demonstrated that tooth loss is associated with esthetic, functional, psychological and social impacts for individuals. However, not all subjects seek treatment immediately after tooth loss, even when desire for replacement is strongly expressed. The aim of this study was to evaluate the perception of patients submitted to tooth extraction about factors associated with tooth loss and prosthodontic treatment, at the time and after extraction. A convenience sample of 211 consecutive patients were clinically evaluated and answered to a questionnaire about perceived impacts and prosthodontic treatment needs. Data were collected at the time of extraction and after a 3-month time interval. Perceived impacts were high (21 to $76 \%$ at the time and 35 to $87 \%$ after extraction). From $72.5 \%$ patients who expressed intention of immediate replacement of edentulous spaces, only $8.1 \%$ had actually been treated. Financial limitation was considered the most important factor that restricted access to treatment. Bivariate statistical analysis showed association between immediate dental replacement and anterior tooth loss $(\mathrm{p}=0.00)$ and extension of edentulous space $(p=0.01)$. Position of lost teeth was associated to perceived functional limitation $(p=0.03)$. Worsened appearance was associated to tooth loss in the maxillary arch $(\mathrm{p}=0.02)$, and desire of prosthodontic treatment was associated to the extension of edentulous space $(p=0.05)$. Perceived impacts were more frequent in women than men. It was concluded that although patients usually expressed prosthodontic treatment needs, clinical and financial issues are determinant factors for tooth replacement.
\end{abstract}

Key Words: perception, extraction, dental prosthodontics.

\section{INTRODUCTION}

Self-perceived prosthodontic needs are determined by a sort of functional, esthetic, psychological and social impacts due to tooth loss $(1,2)$. These impacts have detrimental effects on oral health related to quality of life (OHRQoL) measures $(3,4)$ and different levels of prosthodontic intervention are needed as a standard of care to improve condition of edentulous patients (5).

Nevertheless not all patients with incomplete dental arch need treatment perceive their condition as harmful or deleterious (6). Clinical factors, like number and location of absent teeth, age, gender, impaired function, discomfort and dissatisfaction with appearance, and other sociodemographic, cultural and financial determinants are known as important ingredients of perceived treatment needs and, as consequence, essential aspects of clinical decision making (7-10).

Another issue that influences demand for prosthodontic treatment is the time between tooth loss and seek for treatment. It was hypothesized that selfperceived need and expressed desire for replacement are greater at the time of tooth loss (11). It was also suggested that self-perceived treatment need might be overestimated because many patients do not seek immediate intervention, especially when anterior teeth are not involved, and patients need time to understand the potential impacts of tooth loss. Need-demand relation will be dependent on perceived extension of impacts, feasibility and availability of health care services (1).

This study assessed patients' perceived impacts of tooth loss and prosthodontic needs at the time of extraction and if their perceptions change after a short-term interval.

\section{MATERIAL AND METHODS}

A short-term prospective cohort study was designed. Data were collected at two stages: at the time

Correspondence: Prof. Dr. Cláudio Rodrigues Leles, Departamento de Prevenção e Reabilitação Oral, Faculdade de Odontologia, UFG, Praça Universitária, S/N, Setor Universitário, 74605-220 Goiânia, Goiás, Brasil. Tel: +55-62-35211524. e-mail: crleles@odonto.ufg.br 
of dental extraction and after a 3-month interval (considered as when prosthodontic treatment is suitable after tissue healing and soundness). A convenience sample of consecutive patients was selected during 5 months at the Oral Surgery Clinic at the School of Dentistry of Goiás Federal University. All patients were scheduled for elective dental extraction. Exclusion criteria were third molar surgery (complete dentition), extraction for orthodontic purposes, emergency dental problems with acute symptoms, and patients unable to answer the questionnaire or who refuse to participate. Informed consent was obtained from all participants and the institutional review board approved the ethical aspects of the research protocol.

Clinical examination was performed at the tooth extraction appointments, before surgery. It included socio-demographic variables - age, gender and educational level, and clinical variables - position, extension and number of previous edentulous areas, and reasons for extraction, location of edentulous spaces and number of teeth indicated for extraction. Position of edentulous spaces was classified as anterior, posterior or both, and as upper, lower or both; extension was small (1-2 teeth) or large (3 or more teeth), and number was classified as single or multiple.

Patients' self-perception was examined by a questionnaire that included dichotomous questions about functional, esthetic and psychosocial impacts associated to tooth loss, and perceived prosthodontic treatment need. Questions were based and adapted from the Oral Health Impact Profile instrument (12).

After 3 months, patients were contacted by phone and/or mail and returned for another clinical examination and questionnaire. Patients were questioned if they had replaced the extracted teeth and, if not, the reason why they did not demand for immediate replacement. Perceived consequences of tooth loss were included in another 8 dichotomous questions.

Quantitative analysis was done by descriptive statistics and chi-square test $(\alpha=5 \%)$. SPSS 12.0 software (SPSS Inc., Chicago, IL, USA) was used.

\section{RESULTS}

A total of 211 patients were included in the study (40.8\% male; $59.2 \%$ female). Age ranged from 15 to 82 years, mean $39.5( \pm 14.5)$ years, and $71 \%$ were aged 30 years or more. Low educational level of patients was observed - most participants (59.8\%) had not completed formal basic education.

\section{At The Time of Extraction}

Table 1 shows that, at the time of extraction, most patients (89.6\%) had prior edentulous spaces. Mean number of absent teeth per patient was $10.4( \pm 7.4)$ and edentulous spaces were predominantly large (55\%), posterior (50.2\%) or posterior/anterior (49.2\%), in both arches $(74.1 \%)$ and multiple (86.7\%). Almost $3 / 4$ of patients $(72.5 \%)$ had non-treated edentulous spaces. Most patients (88.5\%) have been using removable dentures (partial or complete) to replace anterior teeth only (15.4\%) or combined anterior and posterior teeth (78.9\%), and $80.7 \%$ of the dentures were in the upper arch exclusively. The main reason for extraction was dental caries in $82.5 \%$ of extracted teeth.

As detailed in Table 2, patients' perceptions of impacts associated to dental loss were considered high at the time of extraction (20.9 to $75.8 \%$ ). Although 96.2\% judged to be important immediate replacement of extracted teeth, only $72.5 \%$ intended to treat edentulous spaces shortly after extraction. Almost all patients believe that prosthodontics have the ability of solving all potential problems that might follow dental loss (92.4\%) and few of them believe in potential risks (26.1\%).

At the time of extraction, perception of impacts was significantly higher in females. Chi-square test revealed differences in perception of worsened digestion $(\mathrm{p}=0.00)$, general health $(\mathrm{p}=0.023)$ and appearance $(p=0.001)$, and being upset because of dental condition $(\mathrm{p}=0.010)$ and worried about it $(\mathrm{p}=0.043)$. No differences in age groups were verified, except for intention to seek treatment shortly after extraction, which was higher in patients older than 40 years $(\mathrm{p}=0.001)$. Frequency of perception of potential risks and benefits of prosthodontic treatment is shown in Table 3. Benefits were mostly associated with esthetics (74.4\%) and function (64.9\%). Reports of potential risks $(\mathrm{n}=55)$ referred to oral discomfort (30.9\%) and injuries to the remaining teeth (29.1\%). Financial constrains was the most reported reason for not treating prior edentulous spaces (82.7\%).

\section{After Extraction}

After tooth extraction, 173 patients (82\%) returned for the second evaluation. From the 38 patients 
that withdrew the study, 50\% were male, $63.2 \%$ were younger than 40 years. Reasons for droput were loss of follow-up (33), not return to appointment (3), 1 moved away for another county and 1 died. The time between tooth extraction and second evaluation ranged from 81 and 217 days, mean time $114 \pm 25$ days (3.8 months).

Only 14 patients (8.1\%) had been treated with prosthodontics in the interval between the first and the second evaluation. Most cases involved substitution of anterior teeth (71.5\%). Table 4 shows that demand for treatment was greater for anterior teeth $(\mathrm{p}=0.000)$ and large edentulous spaces $(\mathrm{p}=0.008)$.

Perceived impacts were higher after extraction, ranging from 34.7 to $93.6 \%$ (Table 5). Although 93.6\% reported that consider prosthodontic is necessary only 8.1\% actually had been treated shortly after extraction, and $63 \%$ of patients believed that they were able to preserve the remaining teeth, even though almost all of them had previously experienced loss of natural teeth.

After dichotomization of variables, chi-square test reveals that position of extracted teeth was related to perception of food avoidance ( $\mathrm{p}=0.03$ ), worse general health $(\mathrm{p}=0.04)$, and negative influence on social relationships $(\mathrm{p}=0.03)$. Patients with extracted teeth in the upper arch perceived worse appearance $(p=0.02)$ and patients with larger edentulous spaces perceived more need of treatment ( $\mathrm{p}=0.049)$. No perceived impacts were associated with the number of edentulous spaces. Female patients expressed more difficult to chew $(p=0.001)$, worsened general health $(p=0.008)$, worsened appearance $(p=0.001)$ and were upset because of dental condition ( $\mathrm{p}=0.001$ ). Patients older than 40 years felt more need of treatment $(\mathrm{p}=0.036)$.

The most commonly reported reason for not seeking treatment after teeth extraction was financial constrain (88.8\%), followed by lack of time (9.0\%), not feeling necessary (7.6\%) and poor motivation (5.6\%).

Differences in self-perception between initial and final examination are given in Table 6. Perception of a worse general health $(\mathrm{p}=0.001)$ and embarrassment $(p=0.009)$ were significantly more reported after extraction. There were also marked discrepancies between frequencies of patients who had reported perceived need of prosthodontics and those who demanded treatment $(\mathrm{p}=0.000)$. Intra-subject agreement between initial and final report of patients ranged from 68 to $96 \%$, and kappa coefficient ranged from 0.32 to 0.52 .
Table 1. Initial clinical characteristics of patients and edentulous spaces (ES) at the time of teeth extraction.

\begin{tabular}{|c|c|c|}
\hline & $\mathrm{n}$ & $\%$ \\
\hline \multicolumn{3}{|c|}{ All Patients $(n=211)$} \\
\hline \multicolumn{3}{|c|}{ Presence of prior ES } \\
\hline Yes & 189 & 89.6 \\
\hline No & 22 & 10.4 \\
\hline \multicolumn{3}{|c|}{$\begin{array}{l}\text { Number of absent teeth/patient } \\
\text { (mean=10.4; } S D=7.4 \text { ) }\end{array}$} \\
\hline 0 & 22 & 10.4 \\
\hline 1 & 15 & 7.1 \\
\hline $2-4$ & 34 & 16.1 \\
\hline $5-10$ & 63 & 29.9 \\
\hline $11-20$ & 53 & 25.1 \\
\hline $21-30$ & 24 & 11.4 \\
\hline \multicolumn{3}{|c|}{ Patients with ES $(n=189)$} \\
\hline \multicolumn{3}{|c|}{ Extension of ES } \\
\hline Short & 41 & 21.7 \\
\hline Medium & 44 & 23.3 \\
\hline Long & 104 & 55.0 \\
\hline \multicolumn{3}{|l|}{ Position of ES } \\
\hline Anterior & 1 & 0.6 \\
\hline Posterior & 95 & 50.2 \\
\hline Both & 93 & 49.2 \\
\hline \multicolumn{3}{|l|}{ Arch } \\
\hline Upper & 8 & 4.2 \\
\hline Lower & 41 & 21.7 \\
\hline Both & 140 & 74.1 \\
\hline \multicolumn{3}{|l|}{ Number of ES } \\
\hline Single & 25 & 13.3 \\
\hline Multiple & 164 & 86.7 \\
\hline \multicolumn{3}{|c|}{ Treatment of ES } \\
\hline Treated & 52 & 27.5 \\
\hline Untreated & 137 & 72.5 \\
\hline \multicolumn{3}{|c|}{ Patients with Prosthodontics $(n=52)$} \\
\hline \multicolumn{3}{|c|}{ Prosthodontic treatment } \\
\hline Fixed & 4 & 7.7 \\
\hline Removable & 46 & 88.5 \\
\hline Both & 2 & 3.8 \\
\hline \multicolumn{3}{|c|}{ Position of prosthodontics } \\
\hline Anterior & 8 & 15.4 \\
\hline Posterior & 3 & 5.7 \\
\hline Both & 41 & 78.9 \\
\hline \multicolumn{3}{|l|}{ Arch } \\
\hline Upper & 42 & 80.7 \\
\hline Lower & 2 & 3.9 \\
\hline Both & 8 & 15.4 \\
\hline
\end{tabular}


Table 2. Frequency [n(\%)] of patients' perceived impacts of tooth loss and prosthodontic treatment at the time of extraction.

Chewing any food became difficult

$160(75.8 \%)$

Digestion became worsened

$121(57.3 \%)$

General health became worsened

$44(20.9 \%)$

Appearance became worsened

$131(62.1 \%)$

Negative influence on social relationships

$86(40.8 \%)$

Unsatisfaction with the dental condition

$108(51.2 \%)$

Concern about the dental condition

117 (55.5\%)

Considered that immediate replacement

$203(96.2 \%)$

of teeth is mandatory

Intended to seek treatment shortly after

tooth extraction

Believed that prosthodontics solve all

potential problems caused by tooth loss

$195(92.4 \%)$

Believed that prosthodontics have potential risks

Table 4. Clinical aspects of edentulous spaces and replacement of extracted teeth $(n=173)$.

\begin{tabular}{|c|c|c|c|c|}
\hline & \multicolumn{2}{|c|}{$\begin{array}{c}\text { Replacement of } \\
\text { extracted teeth n (\%) }\end{array}$} & \multirow[b]{2}{*}{$\chi^{2}$ test } & \multirow[b]{2}{*}{$p$} \\
\hline & No & Yes & & \\
\hline \multicolumn{5}{|l|}{ Position } \\
\hline Anterior & $21(13.2)$ & 9 (64.3) & 23.57 & $0.000^{*}$ \\
\hline Posterior & $122(76.8)$ & 4 (28.5) & & \\
\hline Both & $16(10.0)$ & $1(7.2)$ & & \\
\hline \multicolumn{5}{|l|}{ Arch } \\
\hline Upper & 85 (53.5) & 9 (64.3) & 1.69 & 0.430 \\
\hline Lower & $58(36.5)$ & 5 (35.7) & & \\
\hline Both & $16(10.0)$ & $0(0)$ & & \\
\hline \multicolumn{5}{|l|}{ Extension } \\
\hline Small & $67(42.2)$ & 3 (21.5) & 9.74 & $0.008^{*}$ \\
\hline Medium & 33 (20.7) & $0(0)$ & & \\
\hline Large & 59 (37.1) & 11 (78.5) & & \\
\hline \multicolumn{5}{|l|}{ Number } \\
\hline Single & $122(76.8)$ & 13 (92.9) & 1.12 & 0.289 \\
\hline Multiple & $37(23.2)$ & $1(7.1)$ & & \\
\hline
\end{tabular}

* statistically significant difference $(\mathrm{p}<0.05)$

Table 3. Frequency of patients' perception benefits and risks of a prosthodontic treatment and reasons for not treating edentulous spaces previously, at the time of extraction.

Benefits of prosthodontic treatment $(n=211)$

Esthetics

$157(74.7 \%)$

Better function $137(64.9 \%)$

Better general health

$31(14.7 \%)$

Social benefits

$28(13.3 \%)$

Oral comfort

$12(5.7 \%)$

Psychological benefits

$4(1.9 \%)$

Better self steem

$3(1.4 \%)$

Risks of prosthodontic treatment $(n=55)$

Oral discomfort

$17(30.9 \%)$

Injuries to the remained teeth

$16(29.1 \%)$

Harm to general health

$12(21.8 \%)$

Rejection

$11(20.0 \%)$

Poor adaptation to the denture

$10(18.2 \%)$

Iatrogenic procedures

$6(10.9 \%)$

Others

$4(7.2 \%)$

Reasons for not treating edentulous spaces previously $(n=174)$

Financial limitations

$144(82.7 \%)$

Didn't know about prosthodontic treatment $36(20.7 \%)$

Poor interest

$17(9.7 \%)$

Poor motivation

$17(9.7 \%)$

Negative past experiences

$12(6.9 \%)$

Didn't feel necessary

$8(4.6 \%)$

Others

$41(23.5 \%)$

Table 5. Frequency of patients' perceived impacts of dental loss and prosthodontic treatment after teeth extraction.

Difficulties to chew any food

$136(78.6 \%)$

Avoided to eat any food

$84(48.6 \%)$

General health became worsened

$72(41.6 \%)$

Appearance became worsened

$121(69.9 \%)$

Negative influence on social relationships

$60(34.7 \%)$

Unsatisfaction with the dental condition

$112(64.7 \%)$

Concern about the dental condition

$105(86.7 \%)$

Felt that prosthodontic is necessary

$162(93.6 \%)$

Believed that is able to maintain remaining

$109(63.0 \%)$ teeth throughout life 


\section{DISCUSSION}

Patients' self-perceived needs and expressed desires and expectation are essential parts of an evidence-based model for prosthodontic treatment planning (13). Since patients perceive wide ranges of dental needs, it was assumed that not only clinical aspects of tooth loss influence treatment needs. Human ability to adapt physically and psychologically to changes in oral condition, and cope with these impacts when pain symptoms are absent, may act in addition to external factors like environment and social context.

At the time of extraction self-perception of impacts ranged from $20.9 \%$ to $75.8 \%$ and great part of patients expressed desire for immediate reposition (72.5\%). The psychological effects of tooth loss and previous experiences of different degrees of edentulousness justify the extent of these frequencies. Most patients (89.6\%) had previous tooth loss and 43.6\% had more than one tooth extracted. Trovik et al. (11) found that almost half of patients (47\%) expressed desire for reposition at the time of extraction. Sociocultural characteristics and access to dental service may explain discrepancies in expressed desire for teeth reposition.

Gender and age can influence self-perception of impacts and prosthodontic need. As observed at the time and after tooth loss in the present study, McGrath et al. (14) found that women perceive greater impacts in OHRQoL measures than men. Likewise, intention for dental replacement was greater in older patients $(>40$ years) as observed by Trovik et al. (11) at the time of extraction.

Patients perceive potential benefits more than potential risks of prosthodontics, although many patients that have prior untreated edentulous spaces do not have been treated before (82.7\%). Financial constrains was the most cited reason for not replacement of lost teeth. It is in accordance with McGrath and Bedi (15) that found that social class is the most important predictor in treatment decision making.

Only $8.1 \%$ of patients that returned for the second evaluation have replaced the extracted teeth. Even considering that short-term evaluation may underestimate demand for treatment, it suggests that only a small part of expressed demand at the time of extraction is translated into immediate actual treatment.

Clinical aspects, like anterior position and extension of edentulous space increased motivation for immediate treatment $(6,16)$. Association with clinical variables reinforces that oral function and esthetics are important elements of quality of life. Few occluding pairs of posterior teeth are associated to chewing difficulties (3). However, it is widely known that patients usually tolerate absence of molars and a shortened dental arch with intact anterior sextant $(6,7,17,18)$, but these are not the only predictors of treatment. Consequently, multiple individual and social dimensions are important to justify demand for treatment and may be considered by dental care providers (10).

Even though few patients received treatment after extraction, self-perceived treatment need remained high during second evaluation. Desire for replacement of lost teeth appears to be independent from time interval

Table 6. Comparison of self-perception of patients at the time and after teeth extraction.

\begin{tabular}{|c|c|c|c|c|c|c|}
\hline & \multicolumn{2}{|c|}{$\begin{array}{l}\text { At the time of } \\
\text { teeth extraction } \\
\quad(n=211)\end{array}$} & \multicolumn{2}{|c|}{$\begin{array}{l}\text { After teeth } \\
\text { extraction } \\
(n=173)\end{array}$} & \multirow[b]{2}{*}{$\chi^{2}$} & \multirow[b]{2}{*}{$p$} \\
\hline & Yes & No & Yes & No & & \\
\hline Difficulties to chew any food & 160 & 45 & 136 & 37 & 0.02 & 0.890 \\
\hline General health become worsened & 44 & 146 & 72 & 94 & 16.48 & $0.001 *$ \\
\hline Appearance become worsened & 131 & 78 & 121 & 51 & 2.48 & 0.116 \\
\hline Negative influence on social relationships & 86 & 122 & 60 & 112 & 1.66 & 0.197 \\
\hline Been upset because of dental condition & 108 & 102 & 112 & 61 & 6.88 & $0.009 *$ \\
\hline Felt that prosthodontic is necessary & 203 & 7 & 162 & 11 & 1.94 & 0.164 \\
\hline Perceived need versus demand for treatment & 153 & 50 & 14 & 159 & 171.24 & $0.00 *$ \\
\hline
\end{tabular}

* Statistically significant difference $(\mathrm{p}<0.05)$ 
after extraction, as observed in this short-term study. When esthetics is not involved and oral function is not severely disturbed, decision to treat is highly patientdependent, and normative aspects may play a secondary role in decision-making process. Long-term longitudinal studies are needed to verify to what extent time influences self-perceived impacts and treatment needs and what social and clinical variables are important predictors of prosthodontic needs.

In conclusion, self-perceived detrimental effects of tooth loss were considered high by patients at the time and after extraction. Esthetics and discomfort were mentioned as the major benefit and risk related to prosthodontics. Immediate replacement of extracted teeth was scarce $(8.1 \%)$ and was mainly associated to anterior teeth and large edentulous spaces. Treatment demand was low, frequently due to financial restriction.

\section{RESUMO}

Estudos de autopercepção têm demonstrado que a ausência de dentes pode resultar em impactos estéticos, funcionais, psicológicos e sociais, embora nem todos os indivíduos demandam por tratamento protético imediato após a perda dentária. O objetivo do estudo foi avaliar a percepção de pacientes submetidos a exodontia em relação a fatores associados à perda e ao tratamento protético, no momento e após a perda dos dentes. Uma amostra de conveniência de 211 pacientes consecutivos foi avaliada quanto à condição clínica, autopercepção dos impactos orais e necessidade de tratamento, por meio de exame clínico e questionário, no momento e após 3 meses da exodontia. A percepção de impactos da perda dentária foi alta (21-76\% no momento e 35-87\% após a exodontia). Dos $72,5 \%$ pacientes que relataram pretender a reposição protética imediata apenas $8,1 \%$ realizaram o tratamento. A motivação financeira foi relatada como o maior impedimento para o tratamento. A análise univariada mostrou associação entre reposição imediata e localização anterior da perda $(p=0,00)$ e extensão do espaço desdentado $(p=0,01)$, entre localização da perda e limitação funcional percebida $(\mathrm{p}=0,03)$. O incômodo com a aparência foi relacionado à localização da perda no arco superior $(\mathrm{p}=0,02)$, o desejo por tratamento protético foi relacionado à extensão do espaço desdentado $(\mathrm{p}=0,05)$. Na maioria dos aspectos avaliados a percepção de problemas associados à perda foi maior no sexo feminino. Conclui-se que, embora a necessidade percebida de tratamento protético seja alta, fatores clínicos e sócioeconômicos são determinantes para a realização do tratamento.

\section{ACKNOWLEDGEMENTS}

This study was supported by CNPq (Grant \#134035/2003-8). satisfaction with teeth in relation to dental status in adults. J Oral Rehabil 1995;22:469:480.

2. Omar R, Tashkandi E, Abduljabbar T, Abdullah MA, Akeel RF. Sentiments expressed in relation to tooth loss: a qualitative study among edentulous. Saudis Int J Prosthodont 2003;16: 515-520.

3. Gilbert GH, Meng Xiaoxian M, Oucan RP, Shelton BJ. Incidence of tooth loss and prosthodontic dental care: effect on chewing difficulty onset, a component of oral health-related quality of life. J Am Geriatr Soc 2004;52:880-885.

4. John MT, Koepsell TO, Hujoel P, Miglioretti OL, LeResche L, Micheelis W. Demografic factors, denture status and oral health-related quality of life. Community Dent Oral Epidemiol 2004;32:125-132.

5. McGrath C, Bedi R. Can dentures improve the quality of life of those who have experienced considerable tooth loss? J Dent 2001;29:243-246.

6. Elias AC, Sheiham A. The relationship between satisfaction with mouth and number, position and condition of teeth: studies in Brazilian adults. J Oral Rehabil 1999;26:53-71.

7. Elias AC, Sheiham A. The relationship between satisfaction with mouth and number and position of teeth. J Oral Rehabil 1998;25:649-661.

8. Bowley J. Minimal intervention prosthodontics: current knowledge and societal implications. Med Princ Pract 2002;11:2231.

9. Omar R. The evidence for prosthodontic treatment planning for older, partially dentate patients. Med Princ Pract 2003;12: 33-42.

10. Leles CR, Freire MCM. A sociodental approach in prosthodontic treatment decision making. J Appl Oral Sci 2004;12:127-132.

11. Trovik TA, Klock KS, Haugejorden O. Predictors of Norwegian adult patient' perceived need for replacement of teeth at the time of extraction. Community Dent Health 2002;19:7985.

12. Slade G, Spencer A. Development and evaluation of the oral health impact profile. Community Dent Oral Epidemiol 1994;11:3-11.

13. Rich B, Goldstein G. New paradigms in prosthodontic treatment planning: a literature review. J Prosthet Dent 2002; 88: 208-214.

14. McGrath C, Bedi R, Gilthorpe M. Oral health related quality of life-views of the public in the United Kingdom. Community Dent Health 2000;17:3-7.

15. McGrath C, Bedi R. Severe tooth loss among UK adults - who goes for oral rehabilitation? J Oral Rehabil 2002;29:240-244.

16. Steele JG, Ayatollahi SMT, Walls AWG, Murray JJ. Clinical factors related to reported satisfaction with oral function amongst dentate older adults in England. Community Dent Oral Epidemiol 1997;25:143-149.

17. Witter DJ, Helderman W, Creugers N, Kayser A. The shortened dental arch concept and its implications for oral health care. Community Dent Oral Epidemiol 1999;27:249-258.

18. Owen CP, Locker D. Demographic, psychological, sociologi$\mathrm{cal}$, and economic variables and other factors that justify the need for prosthodontic services, and that help to assess the outcome of care. Int J Prosthodont 2003;16:19-26.

\section{REFERENCES}

